\title{
RESISTÊNCIA FEMINISTA EM MERCADO DE ESCRAVAS, DE LEILA MÍCCOLIS E GLÓRIA PEREZ
}

FEMINIST RESISTANCE IN MERCADO DE ESCRAVAS BY LEILA MIICCOLIS AND GLÓRIA PEREZ

\author{
Evelyn Santos Almeida ${ }^{1}$ \\ Cristiano Augusto da Silva ${ }^{2}$
}

1 Doutoranda em Letras pela Universidade Federal do Espírito Santos.

2 Professor Titular de Literatura Brasileira e Teoria da Literatura na Universidade Estadual de Santa Cruz (UESC).

Via Atlôntica, Săo Paulo, n. 39, p. 71-99, set. 2021. doi: 10.11606/va.i39.181161 
Resumo: Nesse artigo, analisamos poemas da obra Mercado de escravas (1984), de Leila Míccolis e Glória Perez, que problematizam o papel da mulher na sociedade moderna patriarcal, sob a perspectiva da crítica às relações afetivas, relações vendidas como afetivas pela cultura, mas que na verdade se configuram como abusivas (sejam elas familiares ou amorosas). As autoras denunciam, com firmeza e humor, por meio de versos ácidos e debochados, o ambiente machista e tirânico no núcleo familiar e na relação conjugal, a partir de uma voz lírica nitidamente feminista e de uma sólida vontade de resistência ao logofalocentrismo.

Palavras-chave: Leila Míccolis, poesia brasileira, feminismo, relações abusivas. 
Abstract: In this article, we analyze poems from the work Mercado de escravas (1984), by Leila Míccolis and Glória Perez, which problematize the role of women in modern patriarchal society, under the perspective of criticism of affective relationships, relationships sold as affective by culture, but which in fact are abusive (whether family or love). The authors denounce, with firmness and humor, through acid and debauched verses, the macho and tyrannical environment in the family nucleus and in the conjugal relationship, based on a clearly feminist lyrical voice and a solid will to resist logophalocentrism.

Keywords: Leila Míccolis, Brazilian poetry, feminism, abusive relationship. 
Toda vez que uma mulher se defende, sem nem perceber que isso é possível, sem qualquer pretensão, ela defende todas as mulheres.

Maya Angelou

\section{0 feminismo na sociedade brasileira}

Publicado em 1984, próximo ao fim oficial da ditadura civil-militar, o livro Mercado de escravas, de Leila Míccolis em parceria com Glória Perez, é composto por 33 poemas que tematizam, com ironia e humor ácidos, a situação da mulher em meio às relações afetivas institucionalizadas responsáveis pela submissão da mulher, controle da família e, posteriormente, controlada pelo cônjuge.

Glória Perez, conhecida dramaturga brasileira, perdeu sua filha, a atriz Daniella Perez de apenas 22 anos, brutalmente assassinada (GEARINI, 2020) em 1992, pelo companheiro de novela Guilherme de Pádua e sua esposa Paula Nogueira Thomaz, que a mataram por causa da redução de cenas do seu personagem na novela De Corpo e Alma (1992), na qual trabalhavam juntos à época. 0 caso chocou o país devido à brutalidade e ao motivo torpe, homicídio bárbaro, sem chance de defesa, tendo sido Daniela morta com 18 golpes de faca. Infelizmente, a filha da dramaturga foi mais uma vítima de feminicídio, que Glória e 
Leila criticaram e denunciaram em Mercado de escravas, muitos anos antes do referido crime hediondo.

Embora a obra tenha sido escrita por Perez e Míccolis, esta deu prosseguimento à carreira de poeta, enquanto a primeira voltou-se para a teledramaturgia. Por essa razão, ao longo do artigo, nos referimos a Míccolis e não a ambas; de qualquer modo, fica registrada a autoria a quatro mãos.

Leila Míccolis começou sua carreira na década de 1960, período, conforme Heloisa Buarque de Hollanda, "extraordinariamente marcado pelos debates em torno do engajamento e eficácia revolucionária da palavra poética, palavra que, naquela hora, se representava como muito poderosa e até como instrumento de projetos de tomada de poder" (HOLLANDA, 2004, p. 19). Mesmo se lançando na poesia antes da assunção da chamada geração mimeógrafo ou poesia marginal, Leila passa a integrá-la ao lado de Cacaso, Chacal, Ana Cristina Cesar, Paulo Leminski, Nicolas Behr, Glauco Mattoso, Torquato Neto, entre outros. Embora bem distintas, as obras desses poetas possuem a rebeldia jovem, a linguagem avessa a beletrismos, um compromisso com o social, uma visão política do Brasil e do mundo, uma vontade de estreitar os laços entre a ética e a estética.

Mesmo depois do arrefecimento da poesia marginal, nos anos 1980, Míccolis continua sua obra com posicionamentos marginais, "à margem”, no caso, a discussão a fundo em torno da condição da mulher. 
A sua poesia é "caracterizada pelo uso da sexualidade usada como arma de combate, visando à denúncia das condições que as mulheres ocupam na sociedade burguesa" (ABREU, 2008, p. 12). A autora convive com o grupo mais ligado à dita "poesia do desbunde" e do ensimesmamento, mas se posiciona com clareza a partir de uma obra engajada, crítica, política, militante, denunciando a violência, a repressão e as catástrofes cotidianas.

Na sociedade brasileira, historicamente, a mulher sempre foi vista como dona de casa, prendas do lar, mãe e esposa. Em pleno século XXI, esse pensamento ainda não mudou, porque, quando se dispõe a ter uma carreira ao invés de se dedicar exclusivamente à família, a mulher é subjugada, demonizada, pois a concepção social é que ela nasceu apenas para ser mãe, esposa e mantenedora do lar, não servindo para desempenhar outro papel que vá contra os princípios sociais e morais (obviamente masculinos).

Ser mulher nos padrões da sociedade é fatigante, porque existe uma cobrança enorme para que desde criança ela pense em casamento e acredite em contos de fadas, mas quando cresce descobre que o "felizes para sempre" não existe e que alguns príncipes não se transformam em sapos, e sim, em feminicidas.

$A$ violência contra a mulher não é mais um assunto de cunho privado, mas social, pois, em nome de manter a "tradicional família brasileira", várias mulheres se silenciam, se violentam ao não poderem denunciar 
os abusos que sofrem dentro das relações familiares e do casamento, essa instituição que representa para muitas delas um espaço de censura, de tortura e de intenso sofrimento.

Discorrer acerca do significado de feminismo e do papel da mulher na sociedade atual é uma tarefa árdua, pois se intitular feminista é - no entendimento clicherizado do senso comum - estar associada a um grupo de mulheres que ojerizam os homens, de acordo com a premissa conservadora e machista social. Mas o seu real significado é outro e bem mais complexo, conforme se depreende a partir do estudo de várias vertentes do movimento (que vem se constituindo e se transformando há décadas e décadas). A mulher está sempre condicionada ao lugar de subalternidade, no qual ela não tem direitos, apenas o dever de ser submissa ao marido, à família e à sociedade:

O subalterno não pode falar. Não há valor algum atribuído à "mulher" como um item respeitoso nas listas de prioridades globais. A representação não definhou. A mulher intelectual como uma intelectual tem uma tarefa circunscrita que ela não deve rejeitar com um floreio. (SPIVAK, 2010, p. 126)

Spivak afirma que o gênero feminino não pode ter voz, não pode se expressar e, quando o faz, o seu discurso é sempre distorcido ou mal interpretado. Para a atual sociedade machista, discussões sobre gênero, 
feminismo e racismo não são importantes, são banalidades porque há uma tentativa de enfraquecer e deslegitimar esses movimentos que são tão importantes para as mulheres, negros, LGBTQI+, periféricos, entre outros:

falar de racismo, opressão de gênero, é visto geralmente como algo chato, "mimimi" ou outras formas de deslegitimação. A tomada de consciência sobre o que significa desestabilizar a norma hegemônica é vista como inapropriada ou agressiva porque aí se está confrontando poder. (RIBEIRO, 2017, p. 81)

Então, como podemos definir o movimento feminista? Para Garcia, é:

a tomada de consciência das mulheres como coletivo humano, da opressão, dominação e exploração de que foram e são objeto por parte do coletivo de homens no seio do patriarcado sob suas diferentes fases históricas, que as move em busca da liberdade de seu sexo e de todas as transformações da sociedade que sejam necessárias para este fim. Partindo desse princípio, o feminismo se articula como filosofia política e, ao mesmo tempo, como movimento social. (GARCIA, 2011, p. 13)

Podemos defini-lo também como "movimento social cuja finalidade é a equiparação dos sexos relativamente ao exercício dos direitos cívicos e políticos" (OLIVEIRA, 1969, p. 424) ou "movimento destinado a acabar com o sexismo, a exploração sexista e a opres- 
são" (HOOKS, 2018). Ou seja, o movimento feminista não objetiva demonizar ou atacar os homens, mas, sim, prega a igualdade de direitos entre os gêneros em todas as esferas socias. Segundo Nogueira, "desde 1910 que se assiste na psicologia à afirmação das diferenças sexuais para sustentar a inferioridade feminina, limitando a sua esfera de ação, restringindo a sua autonomia e liberdade de movimentos" (2001, p. 10). Bairros, por sua vez, entende que:

Para definir opressão, o feminismo lança mão do conceito "experiência", segundo o qual "opressiva" seria qualquer situação que a mulher defina como tal, independentemente de tempo, região, raça ou de classe social. Cabe notar que essa definição, ao mesmo tempo em que reforça um dos aspectos definidores do feminismo em relação a outros sistemas de pensamento - a importância da subjetividade em oposição a objetividade - também abre a porta para as generalizações Isso, associado ao maior acesso aos meios de propagação de ideias por certos grupos sem dúvida contribuiu para que experiências localizadas fossem tomadas como parâmetro para as mulheres em geral. (1995, p. 459)

A obra de Míccolis é marcada pela resistência e pelo engajamento contra a repressão e a opressão masculinas que vêm do casamento, ou seja, é uma obra que denuncia o abuso sofrido pelas mulheres nesse "contrato" que é visto como harmonioso pela sociedade, mas que para muitas mulheres, provavelmente para a maioria, se configura como um contrato 
de infelicidade, de opressão, de tortura. Tal quadro se explicita com nitidez nos ácidos (e por vezes engraçados) poemas sobre relações afetivas, marcados pela representação crítica do silenciamento e da violência contra a mulher no interior da vida familiar.

Nessa direção, considerando que a poesia de Míccolis e não trata de suas próprias experiências, mas sim, da violência doméstica sofrida por mulheres em relações ditas como afetivas, rompe-se com a ideia totalizante de que a lírica estaria relacionada apenas às questões individuais, pois se notam outras vozes a partir de sua escrita.

Contrário à concepção conservadora de que a lírica estaria em oposição às questões sociais, dado seu caráter subjetivo, Adorno aponta seu forte teor político:

A referência ao social não deve levar para fora da obra de arte, mas sim levar mais fundo para dentro dela. [...] Pois o teor [Gehalt] de um poema não é mera expressão de emoções e experiências individuais. Pelo contrário, estas só se tornam artísticas quando, justamente em virtude da especificação que adquirem ao ganhar forma estética, conquistam sua participação no universal. (2003, p. 66)

Assim, a tensão interna da poesia estaria intrinsecamente ligada aos conflitos externos de seu contexto de produção. Mais adiante, Adorno reafirma sua função social: "só entende aquilo que o poema diz quem 
escuta, em sua solidão, a voz da humanidade [...]" (2003, p. 67).

Por meio da sua escrita irreverente, Míccolis apresenta particularidades da poesia marginal, ainda que ela mesma não se veja como integrante deste grupo. Em entrevista, a escritora analisa a época na qual escreveu a maioria dos seus poemas, falando que a poesia marginal se caracteriza por "uma postura estética deliberada de resistência à ação repressora e repressiva" (MÍCCOLIS, 2007) e que seus poemas pretendiam "debater as convenções sociais que massacram e robotizam as pessoas, inclusive sexualmente" (MÍCCOLIS, 2007).

Dado esse quadro, não há dúvida em afirmar que a obra poética de Míccolis é feminista e se constitui em um campo de resistência das mulheres às relações violentas, de qualquer ordem, sobretudo as de recorte familiar ou conjugal. Por isso,

a poesia de Leila Míccolis é francamente feminista, e com contundência denuncia a situação precária dos cidadãos que, em condição de minoridade (ou seja, distantes de uma posição de poder), sofrem com a dita "maioria" (aquela que, em contextos específicos, usufrui de mando e autoridade, como no verso de Caetano que sintetiza tal situação: "o macho adulto e branco sempre no comando", na canção "0 estrangeiro"). (SALGUEIRO, 2017, p. 340) 


\section{Resistência feminista}

Nos poemas selecionados, um elemento que se destaca bastante é o tom geral de crítica e zombaria ao estado das relações conjugais e familiares, mais especificamente, às relações de cunho supostamente afetivo entre maridos e esposas e, também, entre mães e filhas.

\section{Têmpera de aço ou passaDOR}

Com o fio de ferro de passar minha mãe me batia,

sem clemência.

Não sei como nunca queimou

minha resistência. (MÍCCOLIS, 2013, p. 161)

0 título desta quintilha de única estrofe faz referência ao processo de fundição das ligas de aço com o ferro, que, quando aquecidas, se tornam mais duras e resistentes. A filha - voz lírica do poema - usa essa referência para explicar por que nunca "explodiu" diante da violência, cometida por meio de um objeto doméstico, no caso, o fio do ferro de passar roupa.

Há um jogo de palavras com passa e dor, que podemos entender como uma metáfora, pois, de tanto que já apanhou, a filha não sente mais a aflição das surras, ou seja, a dor passou de tanto que apanhou com o fio do ferro de passar, pois a agressora, a mãe, não tinha benevolência na hora de aplicar o castigo, como a própria vítima destaca. Dessa forma, a voz feminina 
agredida adquire um tipo de resistência à violência sofrida e, por isso, se compara a uma resistência do chuveiro, porque, da mesma forma que a resistência aguenta altas temperaturas e demora para queimar, ela apanha sem se defender, sem revidar, apenas aguenta:

\section{[...] Não sei como nunca queimou} minha resistência.

O eu lírico torna-se resiliente com sua condição de violência ao deixar de sentir a dor física da agressão, enquanto a dor emocional persiste. Continua ali e é relembrada em cada nova surra, como um sinal de que aquele tormento demorará a passar. Os versos, com métrica irregular, com 10/6/3/8/5 sílabas, parecem simular o movimento do ferro sobre a tábua, ou do fio sobre o corpo da filha. A dona de casa não utiliza o objeto ferro de passar para passar a roupa, mas para "passar a dor" para a filha, como se a dor e o sofrimento da mãe fossem transmitidos para a filha pelas surras, como se a infelicidade de uma fosse transmitida para a outra violentamente. Passemos para o próximo poema:

\section{0 dia adia}

Tomar comprimidos

E trocar de maridos. (MÍCCOLIS, 2013, p. 161) 
Quem fala no poema é a "esposa" ou "mulher", haja vista que o objeto de chacota é o "marido". Com apenas dois versos, esse poema apresenta um trocadilho em seu título com as palavras "o dia”, "odiar" e "adiar", por efeito morfossonoro. Nesse efeito, ecoam as expressões "odiar o seu dia" e "adiar o dia a dia". Entende-se que há um adiar da mudança, da separação, porque se odeia o cotidiano e a relação conjugal, daí a necessidade de comprimidos, como atenuante da infelicidade.

0 dístico traz uma rima consoante, reforçada pela rima com o verbo do título; ademais, a rima interna entre os verbos e a métrica regular colaboram para a cadência rítmica do brevíssimo poema, o que contribui para o efeito humorístico. A esposa, atrelada às convenções sociais, precisa se entorpecer para aguentar viver de acordo com os padrões impostos pela sociedade para as mulheres, mesmo que isso signifique a infelicidade ou a troca constante de parceiro, na busca da realização pessoal. A realização maior talvez esteja na própria elaboração do poema, crítico e corrosivo, que condensa uma reflexão acerca da situação de opressão sobre a mulher.

Em termos práticos, a relação conjugal é por vezes comparada a uma "arena na qual o mundo interno de cada um é reencenado, onde necessidades e ansiedades se expressam na expectativa de respostas e soluções" (LEVY; GOMES, 2011, p. 46). No poema percebemos esse ambiente, pois, quando a mulher precisa 
de subterfúgios (comprimidos) para lidar com sua vida conjugal, significa que ela não está vivendo a sua felicidade, mas, sim, satisfazendo as expectativas do outro, que, nesse caso, se confunde com a expectativa social em manter as aparências da união conjugal.

\section{Mercado de escravas}

De dia fazer cafés

e de noite cafunés. (MÍCCOLIS, 2013, p. 162)

Nesse quase-haikai que nomeia o livro, certo cotidiano maçante e massacrante das mulheres no casamento é fotografado, sujeitas que são a tarefas domésticas e desejos dos maridos, mesmo que não queiram. De maneira sintética, a poeta mostra o papel da mulher idealizada pela sociedade patriarcal, na qual ela deve desenvolver o papel de dona de casa e ser submissa ao marido.

Percebemos a violenta dominância do homem sobre a mulher, uma vez que a mulher está como "escrava" do lar, escrava das vontades do marido e silenciada:

Até mesmo a linguagem que empregamos dentro do casamento é reveladora: frequentemente é uma linguagem de posse, não de parceria. Pensamos na palavra "respeito" como um sentimento que a mulher deve ao homem, mas raramente o inverso [...]

[...] Quando as mulheres dizem que tomaram determinada atitude para "ter paz no casamento" é porque 
desistiram de um emprego, de um passo na carreira, de um sonho.

[...] Ensinamos que, nos relacionamentos, é a mulher quem deve abrir mão das coisas. Criamos nossas filhas para enxergar as outras mulheres como rivais não em questão de emprego ou realizações, o que, na minha opinião, poderia até ser bom -, mas como rivais da atenção masculina. Ensinamos que elas não podem agir como seres sexuais, do modo como agem os meninos (ADICHIE, 2015, p. 33-34).

Desde cedo as mulheres aprendem a desistir da sua própria vontade para servirem aos maridos. Aprendem como devem se comportar se quiserem ter um marido, pois os homens não toleram mulheres com opiniões ou com desejos sexuais.

No poema em pauta, a subserviência da mulher ao marido se revela um ciclo ininterrupto, pois ela acaba se tornando a escrava do lar, que vive apenas para os afazeres domésticos e não para realizar seus sonhos. É como se a mulher não tivesse vontade própria e sua vida fosse moldada de acordo com a vontade do outro, nesse caso, o esposo, que não a enxerga como um ser humano, mas, sim, como um objeto disposto a suprir todas as suas necessidades, seus mandos e desmandos. Há uma dicção proverbial, como que transmitindo ensinamentos sobre determinadas situações. Nesse caso, o poema alerta para a rotina da vida a dois, na qual a mulher está sempre condicionada ao papel de escrava do lar pela sociedade patriarcal. Seja no fazer café ou fazer cafuné, o gozo é para o outro, em função 
do outro: se interdita o gozo da subalterna, que nem pode falar nem ter o corpo livre para os prazeres.

\section{Referencial}

"Solteira de aceso facho precisa logo de macho"; "se é nervosinha a casada só pode ser mal trepada"; "viúva cheia de enfado tem saudade do finado"; "puta metida a valente quer cafetão que a esquente".

Mulher não vive sem homem.

A prova mais certa disto é que até as castas freiras são as esposas... de Cristo. Tal regra é tão extremista que não contém exceção: quem sai dela é "feminista", fria, velha ou sapatão".

E com essa bobagem de preconceitos adquiridos que se chega à conclusão, na separação de amores doloridos, de que não houve culpados.

Só feridos. (MÍCCOLIS, 2013, p. 163)

Esse contundente poema, de versos polissílabos e rimas consoantes, desfia, desfila e destila comentários e pensamentos cotidianos, do mais raso senso comum, acerca da vida da mulher, em que só se pergunta se está casada, namorando ou o motivo de estar solteira. Como se a vida se resumisse a uma relação, como se a mulher não pudesse ser feliz sozinha. 
Curioso como ninguém pergunta se ela está feliz, se está realizada na carreira, se tem sonhos.

$\mathrm{Na}$ primeira estrofe, o poema, com forte carga de ironia e linguagem sintética e dinâmica, explicita cenas, situações e impasses cotidianos das relações afetivas dentro do sistema patriarcal, que enxerga a mulher como um ser inferior e frágil, a qual necessitaria de um marido como um alicerce indispensável para sua vida. Esse controle sobre as mulheres é um aspecto historicamente construído:
"Solteira de aceso facho precisa logo de macho";
"se é nervosinha a casada só pode ser mal trepada";
"viúva cheia de enfado
tem saudade do finado";
"puta metida a valente
quer cafetão que a esquente".
Mulher não vive sem homem. [...] (MÍCCOLIS, 2013, p. 163)

Para as solteiras, só restam perguntas do tipo: “e os namorados?", “está sozinha por quê?”, como se houvesse um motivo específico para a mulher não ter um parceiro ou como se a mulher uma espécie de objeto para diversão e não para uma relação - entre sujeitos pensantes, desejosos, autônomos.

Se as casadas estão angustiadas ou nervosas, já levam o apelido de "mal comida", como se a felicidade no casamento fosse algo reduzido a sexo e nada mais: 
"se é nervosinha a casada/só pode ser mal trepada". Parece que todos os problemas da relação não existem se o casal transar diariamente, mas tal concepção é profundamente equivocada, embora sustentada, em alguns círculos machistas, por frases e "pensamentos" como "quer parar de transar, case-se", pois entendem que o desejo sexual diminui com o passar do tempo, e tal diminuição, para tais círculos, fica na conta culposa da mulher, provavelmente porque diminuiu os cafés e os cafunés.

As viúvas ("personagens" constantes nas piadas masculinas) não escapam dos pensamentos maldosos e comentários infelizes: "viúva cheia de enfado/ tem saudade do finado", uma vez que a sociedade vê com maus olhos as viúvas que sentem tesão, como se o sexo tivesse sido enterrado junto com o finado; mas não, elas estão vivas e têm o direito de sentirem prazer novamente, de experimentarem uma nova relação, um novo parceiro sexual. Quando, nos rituais do casamento, se fala "até que a morte os separe", isso pretende significar o mito da fidelidade e da eternidade, não o enterro precoce do desejo daquele que permanece vivo (no poema, a viúva). 0 tom jocoso do poema quer estampar o altíssimo grau de preconceito e de desinformação das pessoas (dos homens, sobretudo) em relação ao desejo, ao corpo, ao erótico feminino.

Quando uma mulher se impõe, resiste às relações abusivas, denuncia a violência, é chamada de femi- 
nista, como se fosse um xingamento; é vista como alguém que não gosta de homem, como se o feminismo fosse uma doutrina que prega o ódio aos homens, mas sabemos que não é nada disso. 0 feminismo luta pelo direito de igualdade entre homens e mulheres, por isso é visto com maus olhos pela sociedade patriarcal, pois coloca em xeque os valores de uma sociedade que se sustenta na opressão contra a mulher, que só respeita mulher casada com homem claro, porque se for lésbica tem que ser apedrejada ou é porque nunca conheceu um homem de verdade para suprir suas necessidades, como se o falo fosse a resposta para tudo, fosse a cura para todos os problemas femininos.

Por conta de todos esses comentários absurdos (mas explicáveis, a partir da prepotência e arrogância machista), a mulher é reduzida a um objeto do homem, sem vontade própria e sem direito de se manifestar para não ser chamada de "puta", "vadia", "feminista", ser vista como aquela que odeia os homens. Infelizmente muitas, milhares de mulheres, nessas supostas relações afetivas foram e são maltratadas, feridas, torturadas e mortas pelos homens que alegavam e alegam amá-las. No entanto, esse homem feminicida incorporou a ideia de que a "mulher que ama" é posse e propriedade dele. Logo, fora desse contexto de posse e obediência, o homem pode e deve agir para "restaurar" a submissão.

Segundo Judith Butler (2018, p.29), “[...] não há como recorrer a um corpo que já não tenha sido sem- 
pre interpretado por meio de significados culturais". Em outras palavras, a mulher já nasce inserida em um contexto cultural no qual seu corpo e sua vida pertencerão à família e posteriormente ao seu marido, pois se depositam na mulher enormes expectativas acerca da maternidade, da fidelidade e do sucesso no casamento, enquanto ao homem é atribuído o papel de provedor e detentor do poder de decisão.

Para Simone de Beauvoir (2016, p. 199), a “história mostrou-nos que os homens sempre detiveram todos os poderes concretos; desde os primeiros tempos do patriarcado, julgaram útil manter a mulher em estado de dependência.” Dessa forma, as práticas e configurações sociais do afeto (casamento, namoro, noivado, relação estável) têm sido utilizadas como ferramenta de controle financeiro, emocional e físico da mulher. Tais questões se mantêm vigentes na sociedade brasileira no século XXI. A instituição do matrimônio é, nesse sentido, o maior exemplo de autoritarismo patriarcal, masculino, machista, pois possibilita que os dispositivos de controle, ou de "aliança", como chama Foucault, em História da sexualidade (1988) sobre o corpo e a vida da mulher se exerçam em plenitude.

Versão privada

Menina,

fina,

precisa se controlar,

portanto,

no WC, 
nunca ir,

isto porque

fazer pipi é vulgar,

ato prosaico demais.

Assim, por ser recatada,

prefere as crises renais... (MÍCCOLIS, 2013, p. 165)

Esse poema expressa de modo ferino o que a sociedade espera das mulheres a respeito do seu comportamento: um controle ferrenho e ascético do corpo, no qual a mulher não tem direito nem às suas necessidades fisiológicas: "fazer pipi é vulgar". Ou seja, as meninas de família que se tornarão mulheres recatadas não devem fazer o que querem e precisam, mesmo que isso inclua inadiáveis necessidades do corpo. É evidente aqui a metáfora da prisão na qual a maioria das mulheres vivem, que começa no seio familiar primário (pai, mãe e irmãos) exercendo o papel de carcereiros, cuja função o marido exercerá posteriormente.

O corpo feminino está sempre sendo controlado por outro, o qual dita as regras a serem seguidas à risca pela mulher, mesmo que signifique problemas de saúde, psicológicos ou físicos: "Assim, por ser recatada,/prefere as crises renais...". Ou seja, é melhor desenvolver patologias do que expressar o que sente e ou denunciar a violência sofrida. Por isso, estão condicionadas pela sociedade a terem "crises renais", que podemos entender, para além do sentido literal no poema, como aguentar abusos em nome da moral 
e dos bons costumes da família patriarcal. Em suma: a mulher é levada, obrigada, induzida a viver em um mundo de aparência, escondendo, abafando, omitindo aquilo que lhe é necessário, prazeroso, gozoso:

Desgraça pouca é bobagem...

Minha mãe se preocupava

quando bem tarde eu voltava

sem saber com que eu andava;

agora que estou casada

e não saio mais de casa,

dias e dias trancada,

entediada, amolada,

ela tá mais sossegada... (MÍCCOLIS, 2013, p. 166)

“Desgraça pouca é bobagem...” aborda de maneira cristalina a reprodução do machismo executada pelas mães, pois a mãe prefere a filha refém de alguém a dona da própria vida, mas "falada" pela vizinhança por sair quando quiser e com quem escolher. Esse tipo de mãe controladora provavelmente perpetua e projeta o próprio modelo de casamento para o futuro e a vida da filha, ou seja, viver para satisfazer o marido, mas nunca a si mesma.

A mãe fica sossegada ao ver a filha quieta em casa, mesmo que isso signifique infelicidade. Para a mãe está tudo bem, pois a filha está trancada em casa, mas com alguém, tem marido e não pode ser vista com maus olhos pela sociedade, como é o caso de mulheres solteiras, vistas, pelo prisma machista, como va- 
gabundas, fáceis ou desinteressantes. A casa é tédio e prisão, que vem curar a filha/mulher da libertinagem incontrolável das ruas, espaço de mistério, aventuras e acasos.

O esquema rímico todo em /a/ encena o tédio e a ladainha da mesmice cotidiana. A filha mostra consciência de ser vítima de abuso, violência psicológica e encarceramento. Sem papas na língua, Míccolis denuncia essa questão gravíssima na história das mulheres e mesmo no avanço do feminismo, que é a "cumplicidade" de certas mulheres, feito a mãe do poema, em relação a valores machistas:

agora que estou casada

e não saio mais de casa, dias e dias trancada, entediada, amolada, ela tá mais sossegada... (MÍCCOLIS, 2013, p. 166)

As reticências marcam o ciclo de submissão da mulher à família e posteriormente ao marido, que não é rompido. Ou seja, a mãe está sossegada porque a filha está vivendo de acordo com seus padrões, mesmo que fique sobre/viva presa, isolada ou esteja sendo violentada, o importante é que ela esteja casada, sem o "risco" de ser difamada pela sociedade. Também, nesse poema, se insinua um tópico frequente na poética de Míccolis, o conflito de gerações, em que a filha (mulher contemporânea) entra em conflito com 
o comportamento da mãe (mulher tradicional). Vejamos outro poema:

\section{Preconceito}

Quando Aída Curi foi currada, estuprada, violada, morta por três homens ouvi gente puritana dizer ainda: - "Bem feito!, quem mandou ser leviana?"... (MÍCCOLIS, 2013, p. 168)

Esse poema faz alusão ao caso Aída Curi, uma jovem de 18 anos brutalmente assassinada nos anos 1960 por dois rapazes de classe média, na cidade do Rio de Janeiro. Ela foi jogada do terraço do edifício no qual um dos rapazes morava, já que resistiu às investidas sexuais dele. Um crime hediondo, cuja vítima seria posteriormente culpada pela sociedade, pois ela fora ao apartamento para ter aula de inglês, mas, na visão da população, alimentada pela ideia machista de que o homem pode dispor do corpo da mulher, ela "estava procurando", estava sendo leviana, como se vê no último verso do poema.

Um feminicídio que ocorreu simplesmente porque os "machos" não conseguem receber um não. A voz lírica feminina se contrapõe ao feminicídio de ambos os homens contra a jovem, demarcando explicitamente os modos empregados de violência, como se 
pode observar nas palavras "estuprada" e "violada", cada uma a compor um verso de apenas um termo e assim se destacarem.

A tonicidade da vogal aberta /a/ repetida por três vezes nos versos "currada/estuprada/violentada" reforça a ideia de assédio e violência contra a mulher, sofridos não só por Aída, mas por tantas mulheres no país e no mundo. "Não aceitem a violência dentro e fora de casa. Denunciem, e vocês terão o Estado brasileiro ao seu lado", promete Débora Prado (2015). Mesmo com a proteção do Estado, com a implementação da Lei Maria da Penha $\mathrm{n}^{\circ} 11.340 / 2006$ (2006) e da Lei do Feminicídio n¹3.104/2015 (2015), várias mulheres ainda são vítimas diariamente de violência física, psicológica, sexual, emocional, financeira etc. e continuam sendo mortas por seus companheiros, ex-companheiros, membros da família.

\section{Considerações finais}

Na obra Mercado de escravas, Leila Míccolis e Glória Perez nos mostram suas faces feministas ao criticarem e denunciarem a violência (doméstica, institucional, consentida, naturalizada) sofrida pelas mulheres, seja física, psicológica, sexual, praticada por seus parceiros ou por suas famílias ou por outros agentes da estupidez. São relações autoritárias e abusivas, travestidas de afeto, carinho ou preocupação com o bem-estar da mulher. 
A postura feminista das autoras se expressa por meio de um humor ácido, ao abordar de forma direta, desmetaforizada e desromantizada, questões delicadas, que incluem a sobrevivência da mulher. Cada vez mais e mais, se faz necessário o movimento feminista na sociedade atual para que a mulher entenda o seu papel na sociedade e lute pela igualdade de direitos e pelo seu livre arbítrio, tão silenciado em vários tipos de relações tidas como afetivas. No discurso da sociedade machista patriarcal:

Se ser feminista, implica, no discurso tradicional, ser uma mulher mal amada, desinteressante do ponto de vista sexual, com problemas de relacionamento interpessoal ou lésbica, as mulheres podem optar por ser "verdadeiras" mulheres, afastando-se assim deste estereótipo limitativo. Assim, a frase "Eu não sou feminista, mas..." representa o facto de muitas mulheres pretenderem distanciar-se dos estereótipos veiculados pela caricaturização do feminismo veiculada pela ideologia tradicional, aceitando, no entanto, a existência de alguns problemas. No entanto é importante perceber que estas posturas inviabilizam por completo qualquer movimento coletivo de pressão. (NOGUEIRA, 2001, p. 9)

O patriarcado apela para estereótipos na tentativa de silenciar o movimento e faz com que mulheres se voltem contra as próprias mulheres que estão lutando pelo direito de todas. 0 feminismo prega sororidade, respeito e empatia uma pela outra e não a competição entre homem e mulher. Tais conflitos e mesmo 
contradições aparecem com força e frequência nos poemas analisados por meio da tensão nos casamentos, namoros, noivados.

A mulher está sempre relegada ao lugar de subalterna na sociedade. As autoras não são, porém, subalternas, ao contrário, são mulheres conscientes e críticas, que colocam sua arte como porta-voz de mulheres silenciadas. No caso de Glória Perez, a dramaturga perdeu a filha vítima de modo brutal e essa terrível memória há de se manter ad infinitum.

A resistência feminista se estende por toda a obra delas como bem aponta o título do livro não deixa ambivalência: Mercado de escravas. Quem são as escravas e quem são os mercadores? Todos sabemos as respostas. Se a opressão, o massacre, o assédio, o feminicídio acontecem de forma ininterrupta, dia a dia, hora e hora, aqui e no mundo, é necessário fortalecer de todas as formas possíveis o alcance do feminismo, a fim de, cada vez mais, alcançar e transformar a consciência das mulheres e também dos homens. Com sensibilidade, justiça, empatia e esclarecimento, quem sabe, essa condição (que vem de séculos e séculos) de subalternidade desapareça, e a mulher possa ser intransitivamente, sem pessoa ou verbo para regê-la, o que quiser ser, enfim, livre. 


\section{Referências}

ABREU, Luciana de Oliveira. $\mathbf{0}$ bom filho à casa torra, isto é: ironia, humor e poesia na obra de Leila Míccolis. 25f. 2008. Monografia (Especialização em Estudos Literários). Universidade Federal do Espírito Santo, Vitória.

ADICHIE, Chimamanda Ngozi. Sejamos todos feministas. São Paulo: Companhia das Letras, 2015. Tradução de Christina Baum.

ADORNO, Theodor W. Palestra sobre lírica e sociedade. In. ADORNO, Theodor W. Notas de literatura I. São Paulo: Duas Cidades; Editora 34, 2003. Tradução de Jorge de Almeida.

BAIRROS, Luíza. Nossos femininos revisitados. Revista Estudos Feministas, Dossiê Mulheres Negras, Florianópolis, v. 3, n. 3, 1995.

BEAUVOIR, Simone de. 0 segundo sexo: fatos e mitos. 3. ed. Rio de Janeiro: Nova Fronteira, 2016. Tradução de Sérgio Milliet.

BRASIL. Presidência da República. Lei $n^{o}$ 11.340, de 7 de agosto de 2006. Disponível em: http://www.planalto.gov. br/ccivil 03/ato2004-2006/2006/lei/l11340.htm>. Acesso em: 04 de jan. 2021.

BRASIL. Presidência da República. Lei $n^{o}$ 13.104, de 9 de março de 2015. Disponível em: http://www.planalto.gov. br/ccivil 03/ato2015-2018/2015/Lei/L13104.htm>. Acesso em: 04 de jan. 2021.

BUTLER, Judith. Problemas de gênero: feminismo e subversão da identidade. 16. ed. Rio de janeiro: Civilização Brasileira, 2018. Tradução de Renato Aguiar.

FOUCAULT, Michel. História da sexualidade I: a vontade de saber. Rio de Janeiro: Graal, 1988. Tradução de Maria Thereza da Costa Albuquerque e J. A. Guilhon Albuquerque. GARCIA, Carla Cristina. Breve história do feminismo. São Paulo: Claridade, 2011. 
HOLLANDA, Heloisa Buarque de. Impressões de viagem: $\mathrm{CPC}$, vanguarda e desbunde 1960/70. Rio de Janeiro: Aeroplano, 2004.

HOOKS, Bell. 0 feminismo é para todo mundo: políticas arrebatadoras. Rio de Janeiro: Rosa dos Tempos, 2018. Kindle Version. Paginação irregular. E-book.

LEVY, Lidia; GOMES, Isabel Cristina. Relações amorosas: rupturas e elaborações. Tempo Psicanalítico, Rio de Janeiro, v. 43.1, p. 45-57, 2011.

MÍCCOLIS, Leila. Desfamiliares: poesia completa de Leila Míccolis (1965-2012). São Paulo: Annablume, 2013.

MÍCCOLIS, Leila. Entrevista com Leila Míccolis. 2017. Disponível em: https://marciasl2001.blogspot. com/2007/06/entrevista-com-leila-mccolis-por-mrcia. html. Acesso em: 04 nov. 2020.

NOGUEIRA, Conceição. Feminismo e discurso do gênero na psicologia social. Psicologia \& Sociedade, 13, 1, 107-128. OLIVEIRA, A. Feminismo. In: Enciclopédia Luso-Brasileira. Lisboa: Verbo, 1996.

PRADO, Débora. Conquista: com sanção presidencial, feminicídio é tipificado no Código Penal brasileiro. Disponível em http://www.compromissoeatitude.org.br/ conquista-com-sancao-presidencial-feminicidio-e-tipificado-no-codigo-penal-brasileiro/. Acesso em: 10 jan. 2021. RIBEIRO Djamila. 0 que é lugar de fala? Belo Horizonte: Letramento, 2017.

SALGUEIRO, Wilberth. Poesia brasileira: violência e testemunho, humor e resistência. Vitória: Edufes, 2017.

SPIVAK, Gayatri. Pode o subalterno falar? Belo Horizonte: Editora UFMG, 2010. Tradução de Sandra R. Goulart Almeida; Marcos Feitosa; André Feitosa. 